\title{
SISTEM INFORMASI PENJUALAN BUSANA BERBASIS OBJECT ORIENTED (STUDI KASUS : GITA MODE)
}

\author{
Dicki Nugraha' $^{1)}$, Lis Suryadi ${ }^{2)}$ \\ ${ }^{1}$ Sistem Informasi, Fakultas Teknologi Informasi, Universitas Budi Luhur \\ ${ }^{1,2} \mathrm{Jl}$. Raya Ciledug, Petukangan Utara, Kebayoran Lama, Jakarta Selatan 12260 \\ E-mail : 1812510723@budiluhur.ac.id ${ }^{1)}$, lis.suryadi@budiluhur.ac.id ${ }^{2)}$
}

\begin{abstract}
Abstrak
Gita Mode adalah suatu toko yang bergerak dalam bidang perdagangan. Proses pencatatan Penjualan Pakaian yang dilakukan di Gita Mode selama ini terasa kurang efisien. Dalam melakukan penelitian di Gita Mode ditemukan permasalahan yaitu adanya kesalahan dalam pengolahan dan penyampaian informasi. Oleh karena itu diperlukan suatu sistem informasi yang dapat mendukung pengelolaan informasi yang ada serta mampu menyelesaikan masalah yang ada dengan menggunakan sistem terkomputerisasi. Pada penyusunan penelitian ini menggunakan metoda SDLC. Adapun kelebihan dari sistem komputerisasi yang ada di Gita Mode adalah dapat mengetahui pencarian data, penginputan data, serta mengetahui Laporan Penjualan secara komputerisasi. Untuk membuat Sistem Penjualan Pakaian terkomputerisasi menggunakan Diagram activity, usecase, class, sequence,fishbond yang berguna dalam menganalisa segala kegiatan dan mengimplementasikan dengan pembuatan program aplikasi menggunakan bahasa pemprograman Vb.Net dan MYSQL sebagai database. sehingga dapat terwujud suatu database berbasis client /server. Adapun solusi dan kesimpulan dari permasalahan yang ada yaitu: Pengelolaan Penjualan Pakaian dikembangkan menjadi terkomputerisasi dengan perangkat lunak (software) yang dikembangkan. Batasan pengembangan lain yaitu dengan membuat sistem informasi Penjualan Pakaian dengan sistem client server.
\end{abstract}

Kata kunci: Sistem Informasi Penjualan, Gita Mode, Vb.Net, Mysql, SDLC, client server

1. PENDAHULUAN

1.1. Latar Belakang

Penggunaan dan pemanfaatan teknologi informasi dan komunikasi secara global dapat digunakan sebagai media bisnis saat ini. Mulai dari pengusaha kecil sampai pengusaha besar sudah banyak memanfaatkan kemajuan teknologi informasi salah satu contoh teknologi yang berkembang pesat saat ini yaitu internet, internet adalah kumpulan jaringan komputer secara terpisah yang tersebar didunia yang mempunyai aturan komunikasi disebut Transmission Control Protocol atau Internet Protocol (TCP/IP) yang memungkinkan data dikirm untuk melalui jaringan telpon atau satelit[1] internet sebagai sarana memenangkan persaingan bisnis mereka. Salah satu kegunaan internet dalam dunia bisnis yaitu untuk mempromosikan produk atau iklan melalui internet. Selain digunakan sebagai media promosi. Gita Mode adalah salah badan usaha perdagangan yang bergerak pada penjualan pakaian, pakaian di produksi sendiri dan memiliki konveksi sendiri. Mengutamakan kualitas, dengan hasil jahitan yang halus, rapi dan indah, Gita Mode juga memberikan jaminan untuk ukuran yang sesuai dengan badan anda. Sehingga pakaian enak dan nyaman dipakai. Telah banyak pelanggan yang memberikan kepercayaannya pada Gita Mode. Gita Mode berpotensi dapat memiliki marketing yang besar, tetapi saat ini sistem pemasaran masih manual sehingga berdampak sempitnya jangkauan pemesanan dan sistem pencatatan transaksinya masih manual, sehingga jika pelanggan mau membeli pakaian harus datang ketoko. Permasalahan lebih detail dirinci sebagai berikut, pertama stock barang tidak update, pengolahan dokumen lama, sering terjadi kesalahan, pencarian berkas lama, penyajian informasi belum memenuhi kebutuhan pimpinan. Tujuan dari penelitian ini adalah membuat sistem informasi penjualan. Sistem merupakan kelompok unsur berkaitan erat dan berhubungan antara satu dengan lainnya, yang berfungsi bersamasama untuk mencapai tujuan tertentu[2], tujuannya dari sistem untuk mempercepat pegolahan data, sehingga pelanggan merasa puas dengan layanan yang diberikan.

\subsection{Studi Literatur}

Dibawah ini beberapa literatur penelkitian sebelumnya:

Penulis Elizaandayni Ginting 2013, judul publikasi Aplikasi Penjualan Berbasis Web Menggunakan Joomla Pada Mutiara Fasion, kesimpulan, Aplikasi ini menyajikan informasi terkait Mutiara Fasion yang ditujukan pada konsumen. Dengan adanya aplikasi ini, informasi tentang produk terbaru Mutiara Fasion dapat terpublikasi dengan baik. [3].

Penulis Ruli Gultom 2015, judul Sistem Informsi Penjualan Pakaian Berbasis Web Pada 
Resnlight Cloth, kesimpulannya Sistem informasi penjualan di Resnlight Cloth saat ini dapat memudahkan dalam proses Pengolahan data. Sistem informasi penjualan yang telah di bangun dapat menangani permasalahan yang ada pada Resnlight Cloth dalam hal pemesanan dan Transaksi. Implementasi sistem yang dirancang dapat meningkatkan pelayanan terhadap konsumen dan menjadikan sistem informasi yang ada menjadi lebih optimal. Analisis dan pengujian sistem yang diimplementasikan pada Resnlight Cloth dapat memudahkan user dalam memoperasiakn sistem tersebut[4].

Penulis Wiwik Sri Rahayu 2014, judul Sistem Informasi Penjualan Berbasis Web Pada Toko Wiwik Collection[5]

\section{METODE PENELITIAN}

\subsection{Metode Pengumpulan Data}

a. Studi Pustaka

Mengumpulkan informasi yang berasal dari buku-buku, artikel-artikel, dan informasi-informasi dari internet sebagai landasan berfikir dan pedoman dalam memulai penelitian, menganalisa, hingga proses perancangan sistem dan pemberian saran.

b. Observasi

Penulis datang langsung ke Gita Mode untuk melakukan pengamatan langsung terhadap sistem dan proses pemasaran serta penjualan yang sedang berjalan di Gita Mode, agar mendapatkan informasi dan data yang dibutuhkan.

c. Metodologi Wawancara

Penulis melakukan wawancara / tanya jawab dengan nara sumber dari Gita Mode untuk mendapatkan informasi mengenai produk-produk yang ditawarkan maupun sistem pemasaran yang digunakan (yang sedang berjalan).

\subsection{Metode Pengembangan Sistem}

SDLC merupakan suatu metode dalam pengembangan SI [6], terlihat lebih jelas pada gambar 1, berikut tahapan-tahapannya:

1. Analisis

Tahap ini mempelajari sistem berjalan untuk mngetahui sebab-akibat permasalahan yang ada,

2. Perancangan

Memahami dan menterjemahkan keinginan pengguna sistem kedalam bahasa komputer, merancang suatu sistem informasi terdiri dari proses"input, file-file database dan output, bahasa yang digunakan, metode dan prosedur serta pengendalian.

\section{Penerapan}

Hasil kakhir dari penelitian adalah sebuah aplikasi komputer yang dapat digunakan user.

4. Pemeliharaan
Pemeliharaan artinya melakukan perbaikan, perawatan sistem informasi.

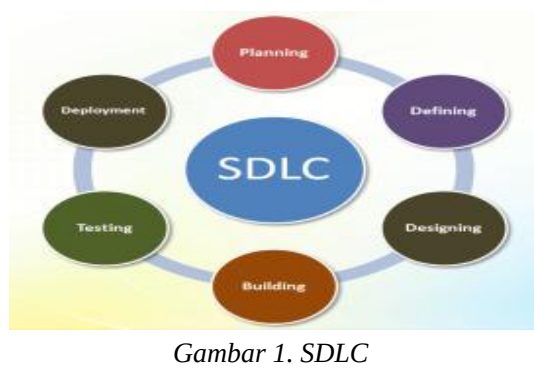

\section{HASIL DAN PEMBAHASAN}

3.1. Fishbone

Pada gambar 2 menjelaskan secara detil masalah dan penyebab yang terjadi saat ini pada tempat penelitian.

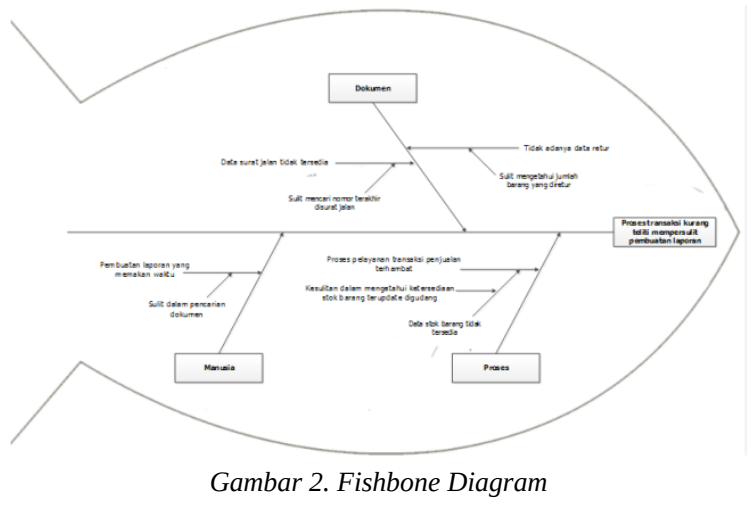

\subsection{Activity Diagram}

Activity diagram menggambarkan aliran kerja atau aktivitas dari sebuah sistem pada perangkat lunak[7].

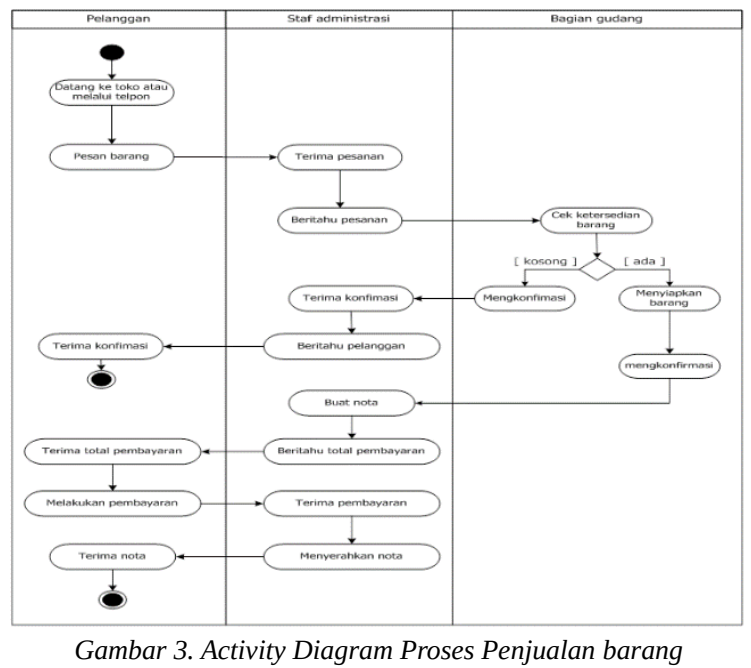


Gambar 3 menjelaskan proses binis penjualan barang, dimulai dari pelanggan datang ke toko lalu menyakan barang yang akan dibeli, pelanggan dilayani oleh staf administrasi lalu staf administrasi konfirmasi ke bagian barang untuk menanyakan apakah barang yang dimaksud pelanggan tersebut ada atau tidak, ada dan tidak adanya barang akan dikonfirmasi oleh bagian gudang.

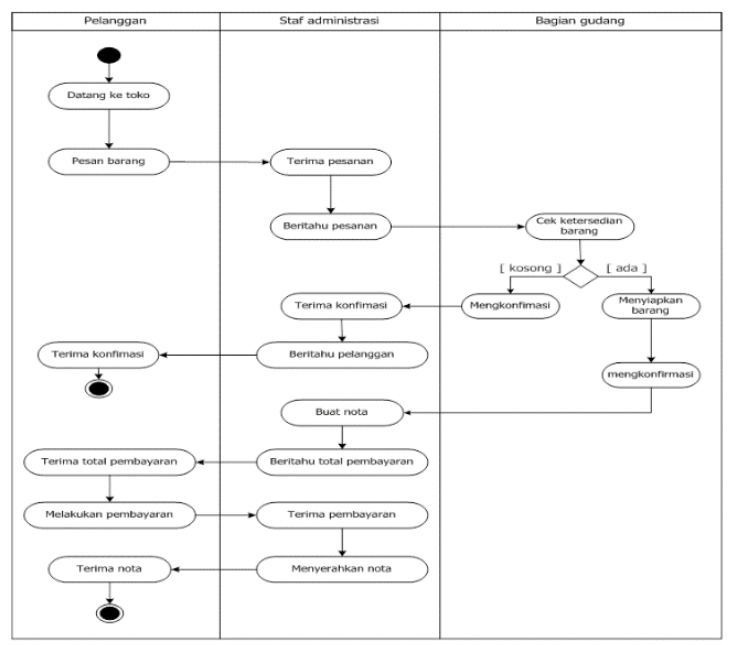

Gambar 4. Activity Diagram Proses Penjualan Eceran

Gambar 4 menjelaskan proses penjualan barang eceran, ada dua cara penjualan yang dilakukan pertama dengan eceran dan kuantitas besar, untuk penjualan eceran, pelanggan cukup datang ketoko menanyakan barang, lalu bayar barang dan diberikan nota tunai. Untuk penjualan dengan kuantias besar biasanya untuk pelanggan yang memang sudah berlanggan. Perbedaannya untuk pelanggan yang dengan kuantitas besar barang akan dikirimkan oleh toko.

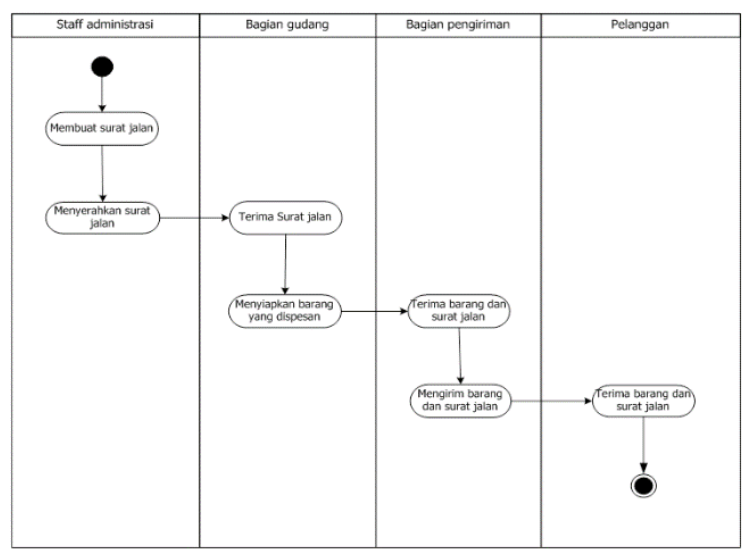

Gambar 5. Activity Diagram Pengiriman

Gambar 5 menceritakan proses pengiriman barang, pengiriman berlaku jika kuantias pembelian besar atau pelanggan memang sudah menjadi pelanggan tetap. Dimulai dari staff administrasi membuat surat jalan, surat jalan diserahkan ke gudang, gudang siapkan barang, surat jalan dan barang diserahkan ke bagian pengiriman lalu barang dikirim sampai diterima pelanggan.

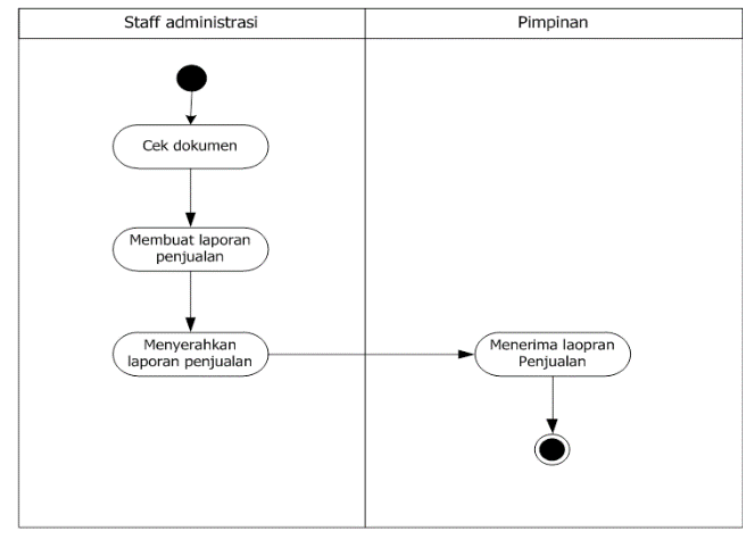

Gambar 6. Activity Diagram Proses Laporan

Gambar 6 menjelaskan proses Cetak laporan dilakukan oleh staff administrasi, setelah dicetak laporan diserahkan ke Pimpinan.

\subsection{Use Case Diagram}

Merupakan pemodelan untuk kelakuan yang dibuat[7].

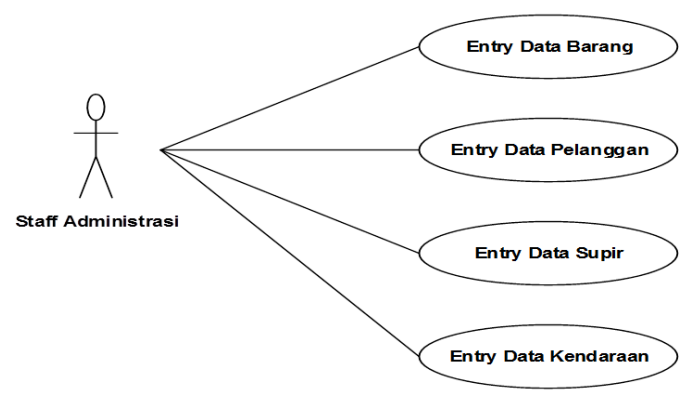

Gambar 7. Use Case Diagram Master

Aktor yang dapat menjalankan sistem penjelasan gambar 7 yaitu aktor staff administrasi, yang dapat dilakukan oleh staff administrasi pada menu master diataranya staff administrasi dapat menginput data barang, data pelanggan, data supir dan data kendaraan

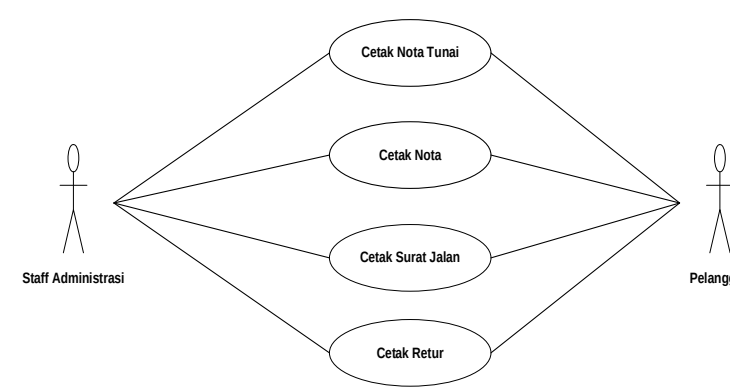


Gambar 8 menggambarkan interaksi aktor pada sistem khususnya pada menu transaksi, gambar 8 ditas terdapat dua aktor yaitu staff administrasi dan pelanggan, aktor aktif staff administrasi dan aktor fasif adalah pelanggan.

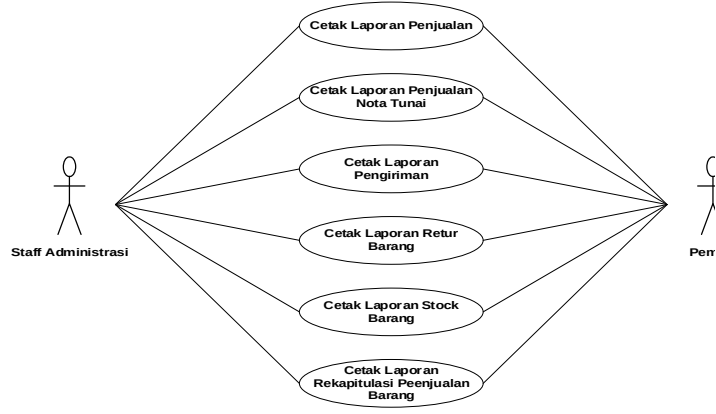

Gambar 9 menjelaskan staff Administrasi dapat melakukan proses cetak laporan penjualan, penjualan non tunai, pengiriman, retur, stok barang dan rekapitulasi penjualan barang.

\subsection{Class Diagram}

Class diagram menggambarkan sistem dari segi pendefinisian kelas-kelas untuk membangun sistem[7]. Seperti pada gambar 10 menggambarkan pendefinisian kelas-kelas untuk membangun sistem.

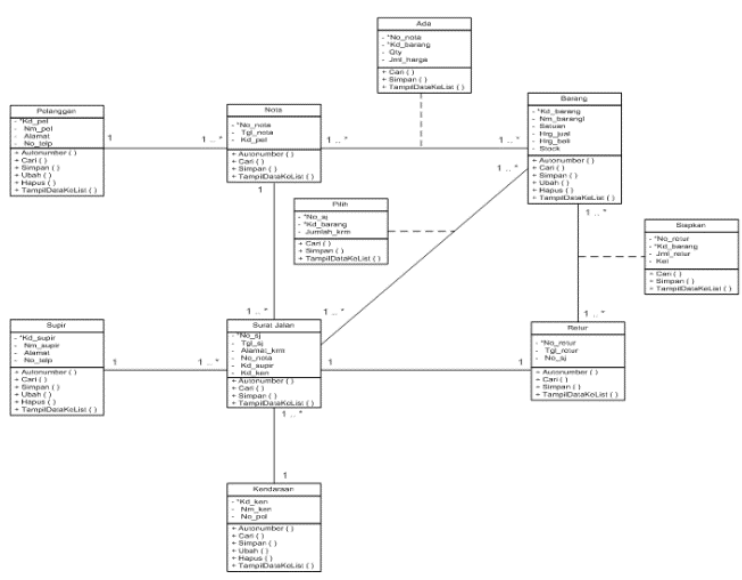

Gambar 10. Entity Class

\subsection{User Interface}

Staff administrasi membuka form data pelanggan. Kode pelanggan akan tampil secara auto number, Staff administrasi mengisi data pelanggan. Terdapat empat buah tombol, tombol simpan jika diklik akan menyipan data, tombol batal membersihkan layar, tombol keluar untuk keluar dari aplikasi. Gambar form terlihat pada gambar 11

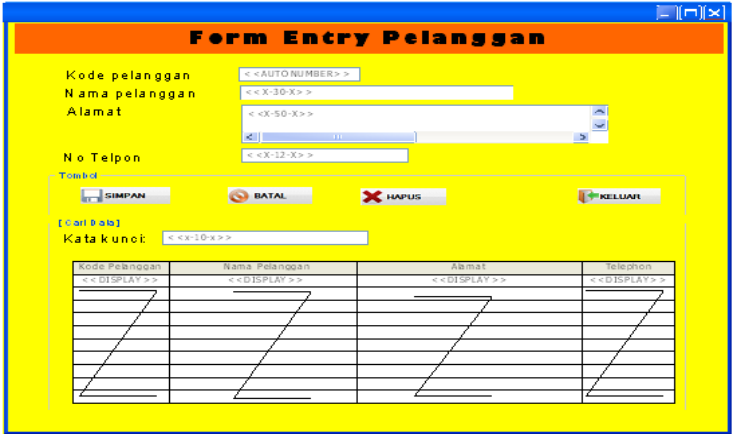

Gambar 11. Form Entry Data Pelanggan

Bagian administrasi membuka Form data Barang. Kode Barang akan tampil secara autonumber. Input data Barang dengan benar. Pada form ini staf administrasi dalam melakukan manipulasi data seperti mengubah data, menghapus data dan lainnya, Gambar form terlihat pada gambar 12

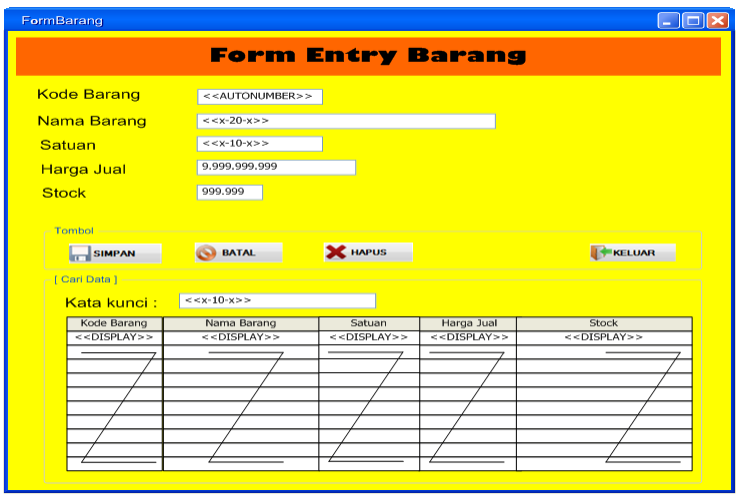

Gambar 12. Form Entry Data Barang

Form cetak nota untuk memasukan data barang yang dibeli oleh pelanggan. Gambar form terlihat pada gambar 13 .

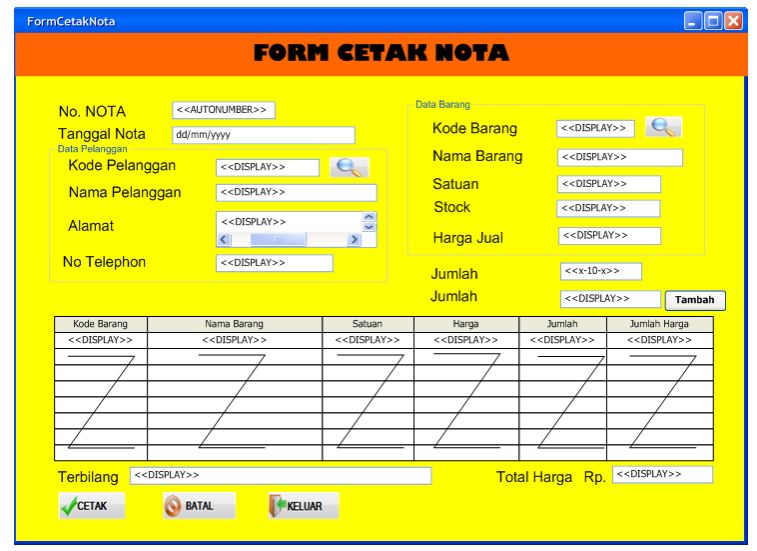

Gambar 13. Form Nota 


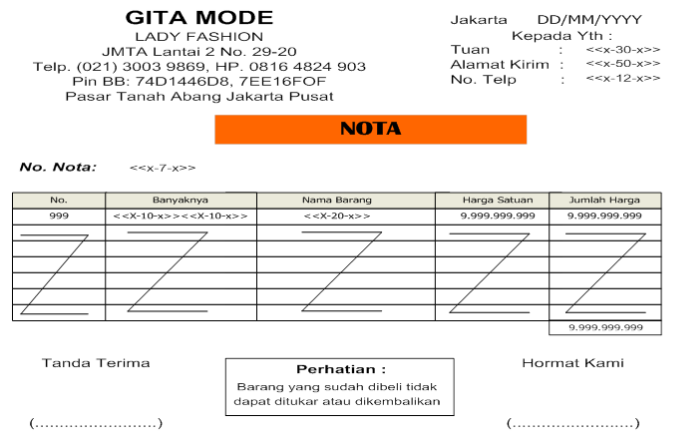

Gambar 14. Hasil cetakan Nota

Gambar 14 hasil cetakan nota penjualan, nota diberikan ke pelanggan. Gambar 15 form untuk mencetak nota tunai

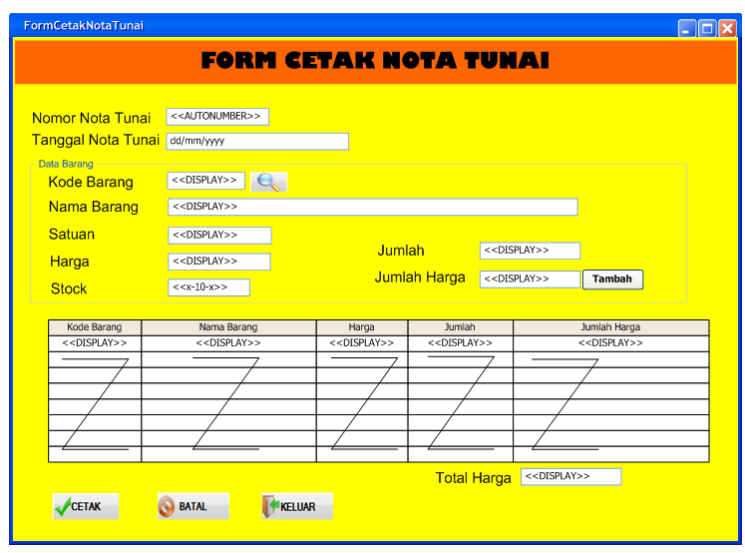

Gambar 15. Form Nota Tunai

Gambar 16 merupakan hasil cetak transaksi nota tunai yang diserahkan kepelanggan saat membeli barang.

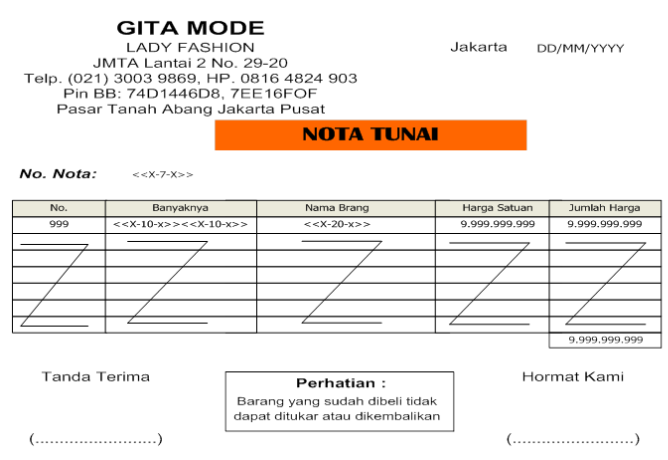

Gambar 16. Hasil cetakan nota tunai

Gambar 17 form untuk mencetak surat jalan yang dibawa saat pengiriman barang

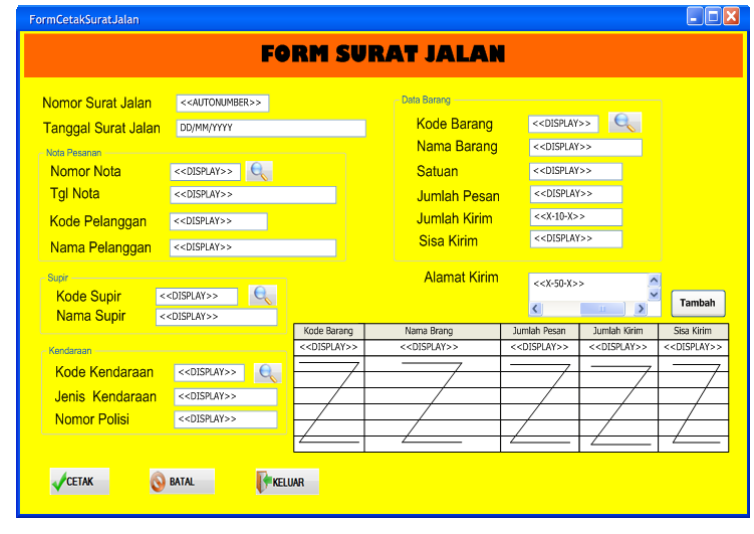

Gambar 17. Form Surat Jalan

Gambar 18 adalah bentuk keluaran cetakan dari form surat jalan .
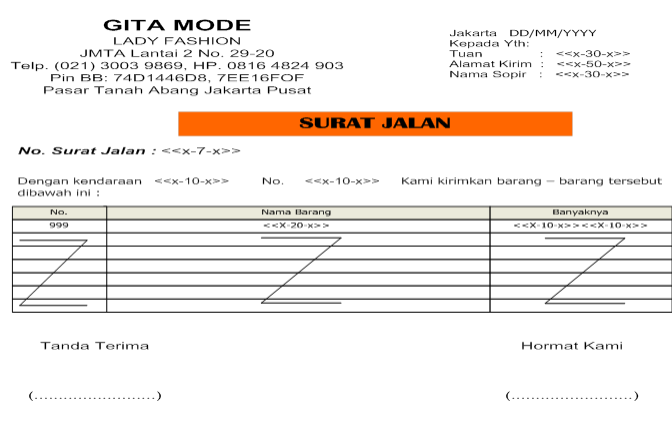

Gambar 18. Hasil cetakan surat jalan

Gambar 19 form untuk menginput data barang yang diretur pelanggan

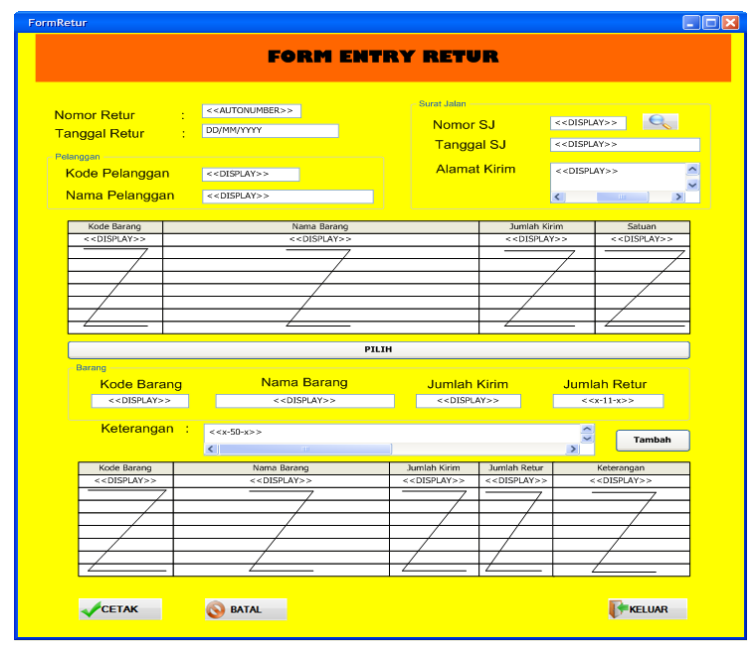

Gambar 19. Form Retur

Gambar 20 kiri hasil cetakan retur sebagai bukti bahwa pelanggan telah meretur barang 


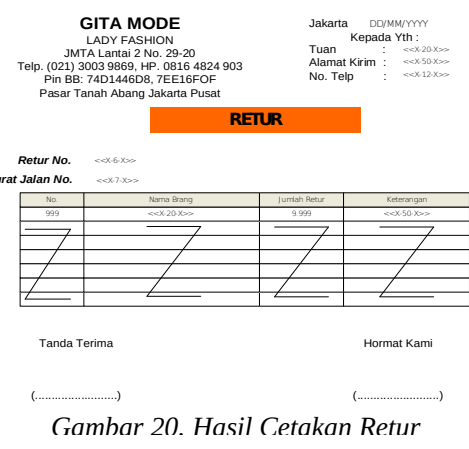

Gambar 21 keluaran cetakan laporan penjualan barang yang diserahkan untuk pimpinan

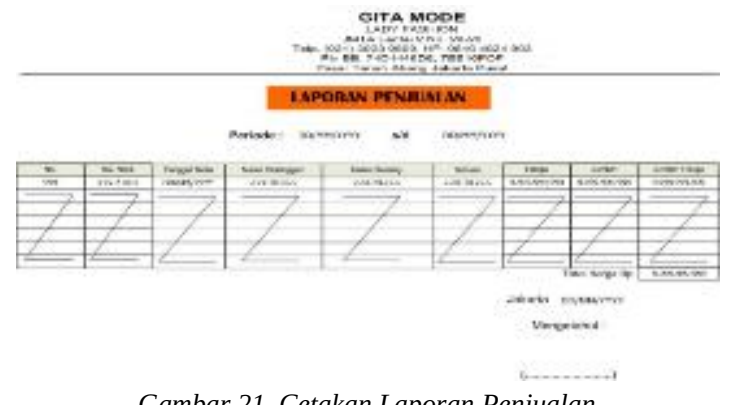

Gambar 22 hasil cetakan laporan pengiriman barang, laporan disrerahkan ke pimpinan

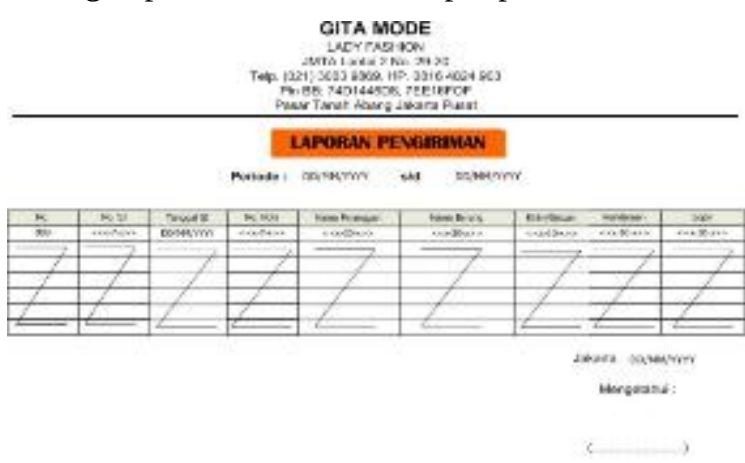

Gambar 22. Cetakan Laporan Pengiriman

Gambar 23 hasil cetakan laporan retur, laporan diserahkan ke pimpinan
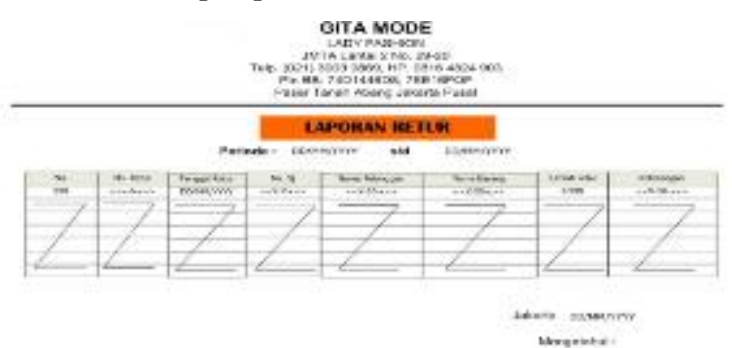

Gambar 23. Cetakan Laporan retur

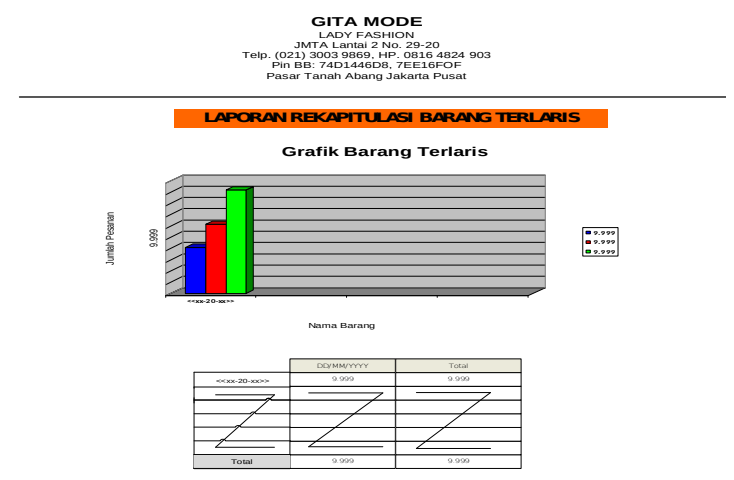

Jakarta DD/MMimr
Mengetahui :

$(\ldots \ldots \ldots \ldots)$

\subsection{Sequence Diagram}

Sequence diagram menggambarkan kelakuan objek pada use case dengan mendeskripsikan waktu hidup objek dan pesan dikirimkan dan di terima antar objek. Sequence diagram entry data pelanggan gambar 25 menjelaskan urutan yang dilakukan aktor pada proses entry data pelanggan

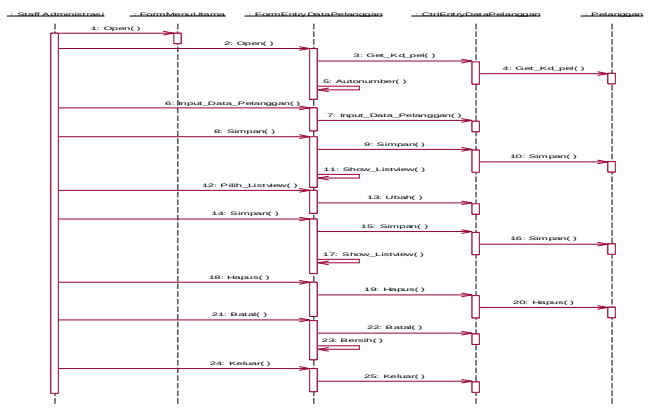

Gambar 25. Sequence Diagram Entry Data Pelanggan

Gambar 26 sequence diagram cetak nota tunai, entity yang digunakan sebanyak 3 entitty

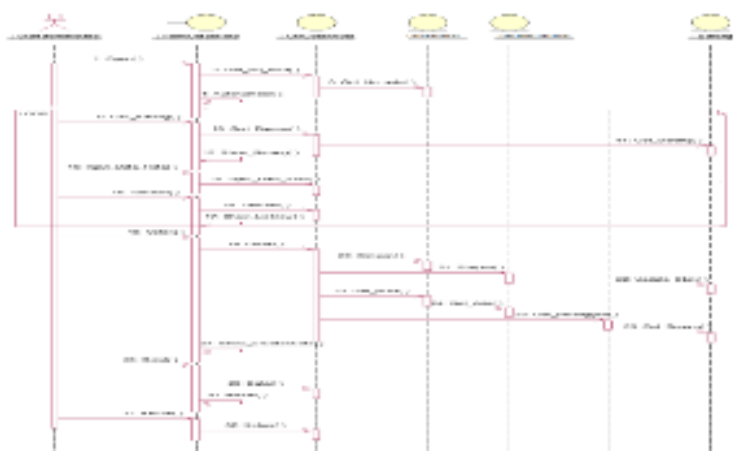

Gambar 26. Sequence Diagram Cetak Nota Tunai

Gambar 26 sequence diagram laporan rekapitulasi barang yang banyak terjual, menggunakan tiga entity 


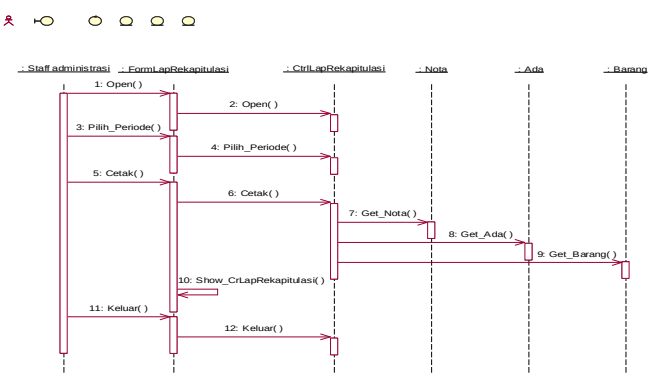

Gambar 27. Sequence Diagram Cetak Laporan Rekapitulsai Barang Terlaris

\section{KESIMPULAN}

Terakhir yang dapat disampaikan pada hasil penelitian ini adalah sebagai berikut:

a. Dengan sistem informasi maka user tidak lagi memikirkan pengurangan stock barang, stock barang sudah di lakukan otomatis oleh DBMS melalui fungsi triger.

b. Pengolahan data dan dokumen terkait penjualan akan lebih cepat.

c. Kesalahan akan lebih minimal karena untuk perhitungan sudah dilakukan otomatis oleh rumus dan fungsi aplikasi

d. Penyajian informasi ke pimpinan dalam bentuk laporan-laporan akan lebih cepat.

\section{DAFTAR PUSTAKA}

[1] Isnanto, Burhan.. "Prototipe SMS Gateway Pemantau Jaringan LAN Dan Network Pada PT Bangka Pesona Media”. Pangkal Pinang : STMIK Atmaluhur Pangkal Pinang. Jurnal Teknologi Informatika Dan Komputer Atma Luhur Vol. 2 No. 1 Maret 2015 ISSN : 2406-7962, 2015

[2] Mulyadi, 'Sistem Akuntansi Edisi 4'. Jakarta: Salemba Emp,2016

[3] Elizaandayni Ginting, 'Aplikasi Penjualan Berbasis Web Menggunakan Joomla Pada Mutiara Fasion'. https://repository.widyatama.ac.id, 2013, Diakses Tgl 20 Juli 2019 Jam :10:30 Wib

[4] Ruli Gultom, 'Sistem Informsi Penjualan Pakaian Berbasis Web Pada Resnlight Cloth'. https://elib.unikom.ac.id, 2015, diakses Tgl 15 Juli 2019, Jam 13:50 Wib

[5] Wiwik Sri Rahayu, 'Sistem Informasi Penjualan Berbasis Web Pada Toko Wiwik Collection'. http://ojs.stmikpringsewu.ac.id., 2014, pISSN : 2339-1103. eISSN : 2579-4221. diakses Tgl 15 Juli 2019, Jam 14:12 Wib

[6] Agitya, Lingga, "Eksplorasi Metodologi SDLC". Sistem Informasi UNIKOM, 2013

[7] Rosa, A.S dan M. Shalahudin, 'Menggunakan UML’. Bandung : Informatika, 2014 